\title{
Anomalous Vessel Behavior Detection Based on SVR Seaway Model
}

\author{
Joo-Sung Kim ${ }^{1}$, Jin-Suk Lee ${ }^{1}$, and Kwang-II Kim ${ }^{2}$ \\ ${ }^{1}$ Division of Navigation Science, Mokpo National Maritime University, Mokpo, Korea \\ ${ }^{2}$ Division of Marine Industry and Maritime Police, Jeju National University, Jeju, Korea
}

\begin{abstract}
The identification of anomalous behavior of own vessel and its targets is one of the most important task to ensure safety of navigation. In particular, it is essential to determine the anomalous behavior of a ship in the decision-making process. The existing anomalous behavior detection method defines the anomalous behavior by judging the abrupt changes of a ship's movement. However, the navigational data that observed in actual marine accidents were often showed as a normal condition. It means that if there were persistent differences at certain duration, the accumulated data could become large enough to cause of an accident. In this study, the ship's anomalous behavior was determined based on the SVR seaway model and its route extraction method. It was intended to propose a method of defining acceptable maximum and minimum values to determine the anomalous behavior by assigning navigational data to the location basis. For the verification of the proposed method, it was constructed that virtual route and targets which are similar to the actual navigational environment. As a result of the simulation, anomaly detection data on the anomalous behavior were presented. It is expected that the proposed method could be a decision-making support tool to mariners and contributes to the reduction of marine accidents related on the anomalous behavior.
\end{abstract}

Keywords: Vessel Traffic Services, Anomalous behavior, Seaway model, Support vector regression, Machine learning

Received: Feb. 26, 2019

Revised : Mar. 13, 2019

Accepted: Mar. 14, 2019

Correspondence to: Kwang-II Kim (kki@jejunu.ac.kr)

@The Korean Institute of Intelligent Systems

cCThis is an Open Access article distributed under the terms of the Creative Commons Attribution Non-Commercial License (http://creativecommons.org/licenses/ by-nc/3.0// which permits unrestricted noncommercial use, distribution, and reproduction in any medium, provided the original work is properly cited.

\section{Introduction}

Despite the efforts to develop marine information communication technologies in order to prevent accidents, marine accidents has been occurring without interruption. According to the statistics of Korean Maritime Safety Tribunal (KMST), 9,413 marine accidents have occurred in the last five years from 2013 to 2017. Out of these accidents, 1,219 marine accidents have occurred in nearby entrance of waterways in harbors and its approaching area [1]. In particular, recent marine accidents such as the VLCC Wu Yi San in port of Yeosu on January 31, 2014, and the passenger ship Sewol in the vicinity of Jindo island on April 16, 2014, cause serious economic and human losses including critical marine pollution. Therefore, in order to prevent potential accidents and to maximize the efficiency of marine traffic, ships are required to navigate in the designated routes within a harbor and its access waters. In these reasons, Vessel Traffic Service (VTS) has been established to monitor relevant ships compliance with rules and regulations. The VTS has generally installed by authorized governments in necessary waters in order to promote safe and efficient navigation and prevent such accidents in the basis 
of 'IMO Resolution A.857(20) on Guidelines for Vessel Traffic Services', the article 36 of 'Maritime Safety Act', the chapter 4 of 'Act of Ship Arrival and Departure' and 'Rules of Implementation for Vessel Traffic Services' [2-5].

When a ship sails in a particular navigational area, the master or an officer of watch shall monitor own ship's position and also verifies that the ship is sailing in the proper location or route. In addition, they confirm the abnormality by monitoring the appropriate data to be taken at the situation [6, 7]. At this time, operators judge abnormalities of the navigational data based on ship's position. In general, they check ship's navigating route, appropriate speed and proper course to be taken. These activities could be considered a type of an anomalous behavior detection by humans $[8-10]$. In the existing anomalous behavior detection method, the anomaly is judged by sudden changes of the navigational data [11, 12]. In these kinds of methods, it is impossible to distinguish the action taken to escape the risk in the unexpected navigational environment [13]. Therefore, it is necessary to develop the supporting tools for the decision maker of ship's navigation in order to determine the anomaly in advance including unexpected situations.

In this study, it is intended to propose the anomalous behavior detection method based on the ship's navigational route. In the basis of the route extraction method proposed in the SVR seaway model, ship's navigational data are assigned to the location basis, and acceptable maximum and minimum limitation values are defined. The anomalous behavior is determined by comparing the navigational data between a ship that breaks away from the route and the others that navigate along the route. For the verification of the proposed method, it was constructed for virtual route and targets' trajectories which are similar to the actual navigational environment. The simulation route consists of the hydrological characteristics of Incheon harbor as a model.

\section{SVR Seaway Model}

In general, a ship navigates along a designated route within a harbor and its approaching area. At this time, the movement of the ship within the route appears in a regular pattern. The proposed method for identifying the anomalous behavior is based on the ship's navigational pattern. Therefore, the recognition and presentation of the particular navigational pattern are important factors in the determination of the anomalous behavior. In this study, the SVR seaway model was used to determine the anomalous behavior. The SVR seaway model proposed by
Kim el al. [12] is a method of learning data-set using support vector regression (SVR) technique. As a result of the algorithm, the trajectory model are extracted [14-17]. It is known that the method can be applied to the navigational environment where the traffic situation is complicated such as ports and adjacent waters because the extracted reference route is defined based on the individual navigational data.

The characteristics of data learning through SVR are determined by selecting the number of support vectors to be learned according to the selected parameters [18, 19]. Thus, the output model through the SVR can be extracted without being limited by the size of the dataset. Because of this feature, the SVR seaway model is suitable for the application to harbors and its approaching waters that show frequent changes of the navigational patterns. In addition, since the patterns can be analyzed using the navigational dataset for a specific period selected by the user, it is possible to obtain the extracted route model that reflects the navigational characteristics for the specific period [20].

While the traditional pattern recognition techniques are based on empirical risk minimization methods using statistical pattern recognition according to the distributed pattern of data, SVR minimizes the probability of error for the data with fixed but unknown probability distributions and structural risk minimization [21, 22]. The v-fold cross-validation and grid search techniques were used to select the kernel functions and the optimal parameters to construct the SVR model for extracting the navigational data model. This technique is derived from the LIBSVM algorithm proposed by Hsu et al. [23]. Since then, it has been widely used and recognized for its high reliability. It also has been utilized to construct optimal parameter combinations in various data learning algorithms.

Figure 1 is the process of extracting the navigational model. Firstly, the navigational data are collected and the data are classified into the target area. Each ship's dataset is classified according to the navigational section and converted into the data structure to form datasets for learning. The trajectory data for learning constitutes lower datasets by curvature detection and extraction of way points. These lower datasets become the final dataset for learning. In the learning process, the final trajectory data are selected through data scaling and parameter selection. As a result of the learning, the final trajectory model is extracted and a database of trajectory models is constructed. Meanwhile, the system extracts the data model of the course and speed in the same way by the navigational model extraction method. The extracted voyage information data are assigned to 


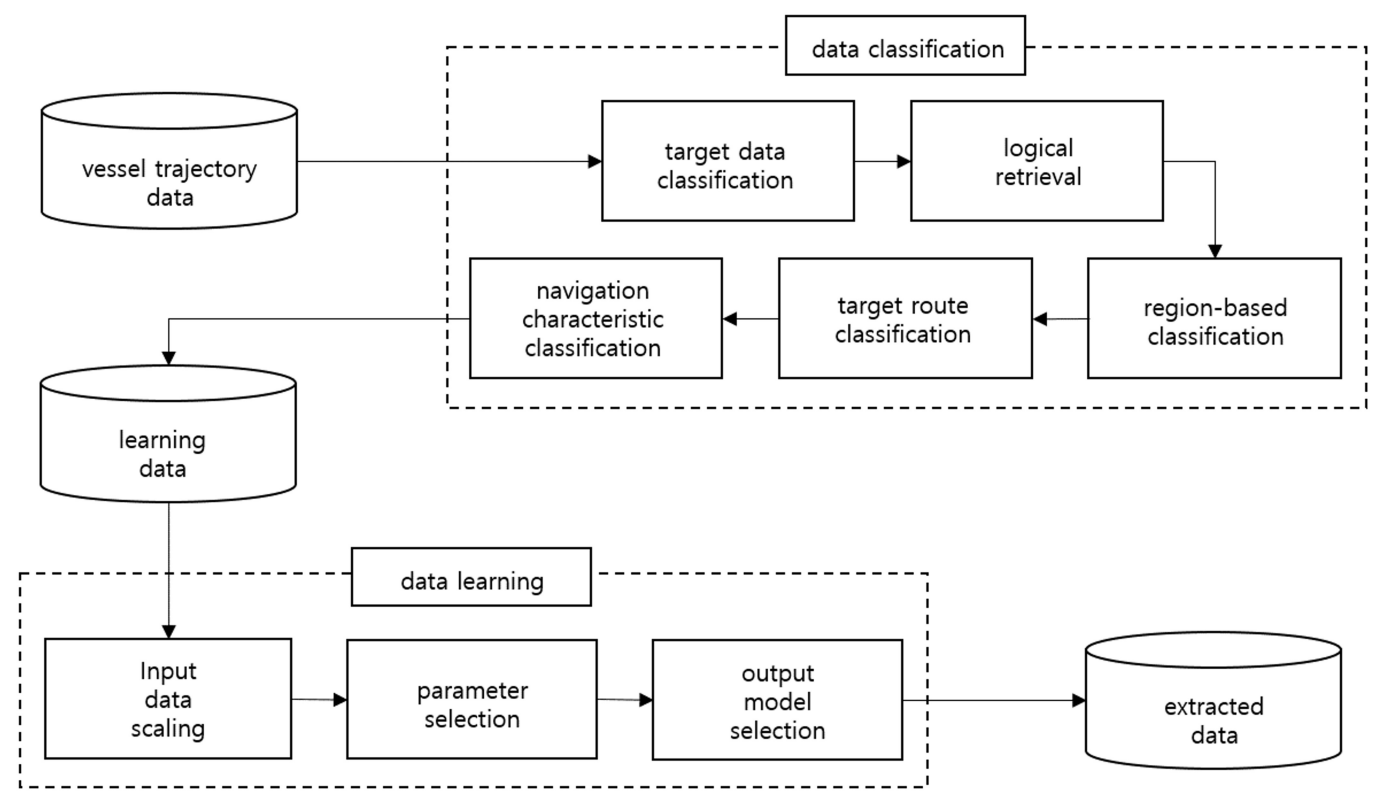

Figure 1. Procedure of SVR seaway model.

the location-based data space, and the extracted data are used as the reference to determine the anomalous behavior.

\section{Anomalous Behavior Detection Method}

The anomalous behavior of a ship is the cause of marine accidents such as collision and stranding. Early detection of such anomalous behavior can be used as a risk signal in advance. Therefore, it is necessary to develop a method of determining whether a ship is navigating properly in a given situation. It can be defined as the anomalous behavior including all unexpected navigational data alterations. The existing anomalous behavior detection method determines the anomalous behavior by judging the ship's abrupt motion changes. However, the constantly accumulated data can be large enough to cause of an accident. Unfortunately, if the navigational data change slowly, decision makers could not be noticed the possibilities of accidents in advance. Normally, they judge anomalous behavior according to the certain criteria that set by themselves and the systems that supporting anomalous behavior detection also judges the anomaly based on the fixed value. However, the user-determined criteria cannot be considered to have objective credibility.

Figure 2 shows the concept of anomalous behavior detection. In the case of Figure 2(a), the ship has swerved from the route without navigating along the designated route. It can be considered that the ship may not be normally navigating when it has exceeded a certain distance from the route. However, decision makers have difficulties in defining the standard of route data. In the proposed method, the extracted route model becomes the reference data. In case of Figure 2(b), there is a difference between the reference data and the ship's course regardless of the ship's current location. In case of Figure 2(c), the ship's speed is different from the reference data regardless of the position and the course. The case (a), (b), and (c) in Figure 2 can be independent conditions for determining the anomaly. In the case of (b) and (c) in Figure 2, if the course or speed data are not normal, there is a high possibilities of breakaway in the near future regardless of the current position.

The data presented by the SVR seaway model are objective references when comparing with the values arbitrarily determined by the user. In the proposed method, it is important to reconstruct the navigational data such as ship's route, course and speed. Even if a ship provides its own planned route, it is essential to reconstruct reliable navigational data. As shown in Table 1, there are 8 cases of identifying anomalous behavior. If any of the position, course, and speed data has exceeding the reference value, it can be defined as the signal of anomalous behavior.

In the proposed anomalous behavior detection method, it can be obtained for the satisfactory results based on accurate and reliable route, course, and speed model. The navigational data models here are derived according to the process of SVR seaway model extraction, and the following procedures are performed 


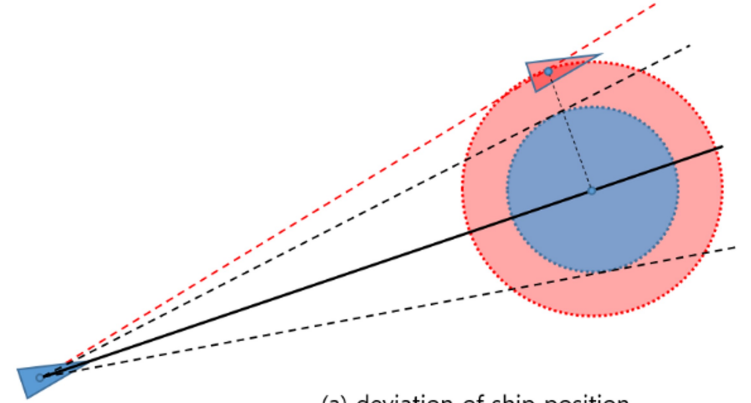

(a) deviation of ship position

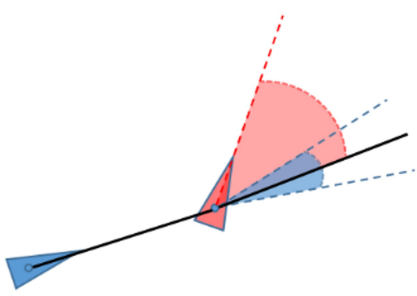

(b) deviation of ship course
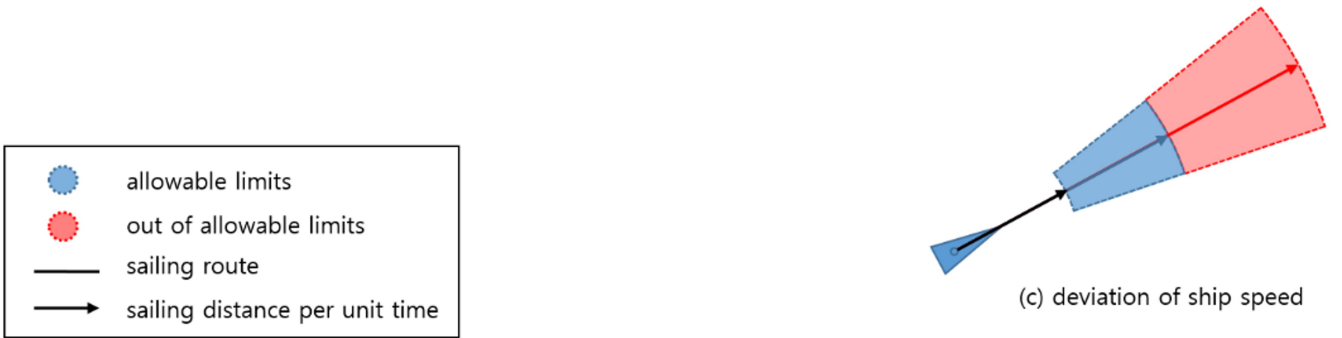

(c) deviation of ship speed

Figure 2. Concept of anomalous behavior detection. (a) Deviation of ship position, (b) deviation of ship course, and (c) deviation of ship speed.

Table 1. Possible cases of anomalous behavior

\begin{tabular}{ccccccc}
\hline \multirow{2}{*}{ Ship's behavior } & \multicolumn{2}{c}{ Position } & \multicolumn{2}{c}{ Speed } & \multicolumn{2}{c}{ Course } \\
\cline { 2 - 6 } & Codition & Detection & Codition & Detection & Codition & Detection \\
\hline \multirow{2}{*}{ Abnormal } & Detected & Abnormal & Detected & Abnormal & Detected \\
& Abnormal & Detected & Abnormal & Detected & Normal & Not detected \\
& Abnormal & Detected & Normal & Not detected & Abnormal & Detected \\
& Abnormal & Detected & Normal & Not detected & Normal & Not detected \\
& Normal & Not detected & Abnormal & Detected & Abnormal & Detected \\
& Normal & Not detected & Abnormal & Detected & Normal & Not detected \\
& Normal & Not detected & Normal & Detected & Abnormal & Detected \\
& Normal & Not detected & Normal & Not detected & Normal & Not detected \\
\hline
\end{tabular}

to construct the anomalous behavior detection algorithm.

First, the extracted route, course and speed models are selected through data learning. Second, the final reference models are constructed by assigning navigational data according to the ship's position.

Second, the final reference models are constructed by assigning navigational data according to the ship's position.

Third, the approximate point of the extracted trajectory is searched according to the present position of the target vessel for the anomalous behavior judgment.

Fourth, the navigational data of the target ship are compared with the reference data pattern and if the result values were exceeded from the limitation, it is defined as the anomalous behavior.

Figure 3 is the flow chart for explaining the anomalous behavior determination procedure. The extracted route, course, and speed data are used as the reference values for determining the anomalous behavior, and the data are used individually for the determination. If any one of the value indicates as an anomaly, the ship is defined as the anomalous behavior.

The example of the method for selecting the criteria is shown in Figure 4. The upper and lower limitation are set based on the extracted values through the data learning. If the results are existed within the range of $25 \%-75 \%$, it is considered as the normal navigation level. The case of $9 \%-25 \%$, and $75 \%-91 \%$ shall be the cautious navigation level. The case of $0 \%-9 \%$, and 


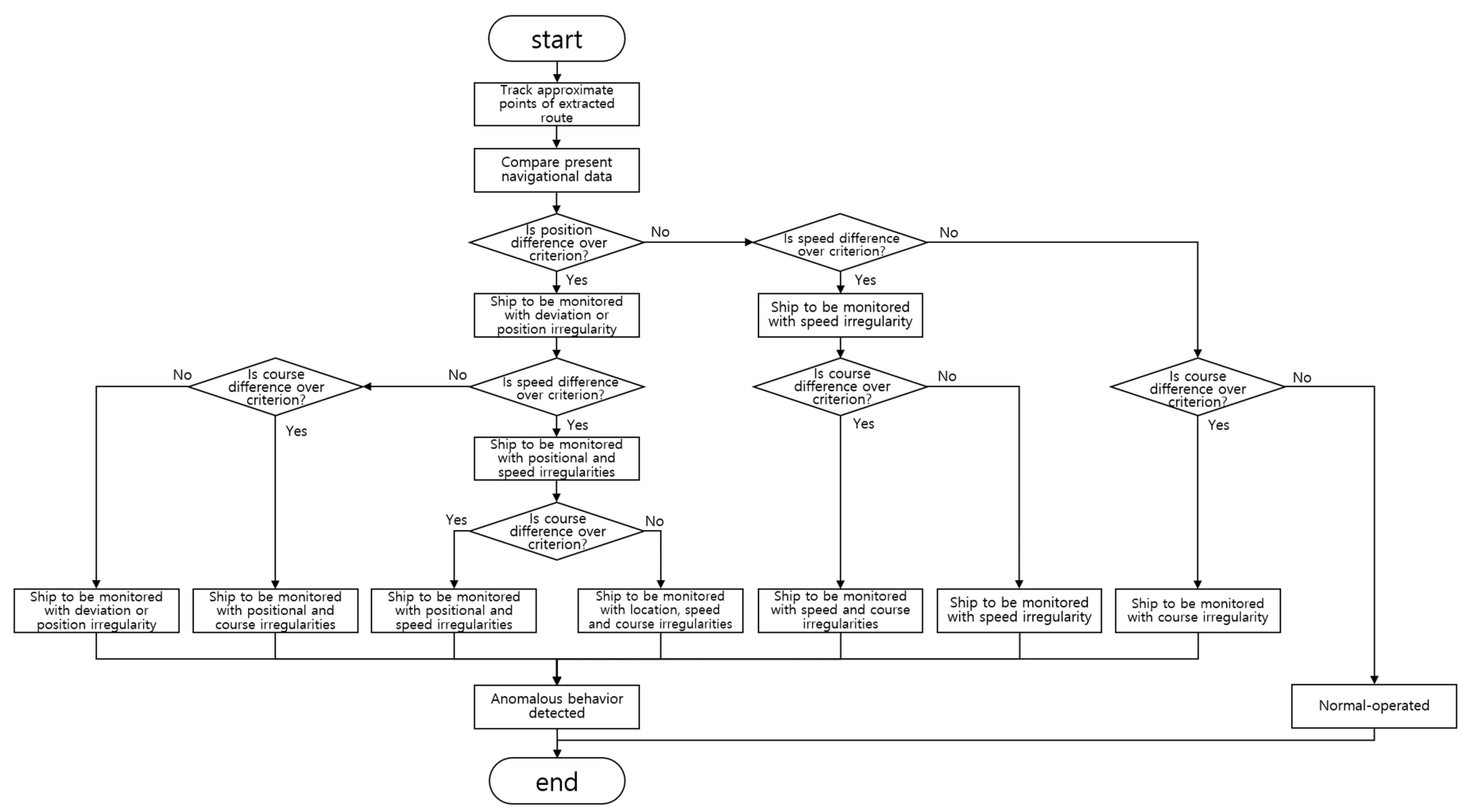

Figure 3. Anomalous behavior determination procedure .

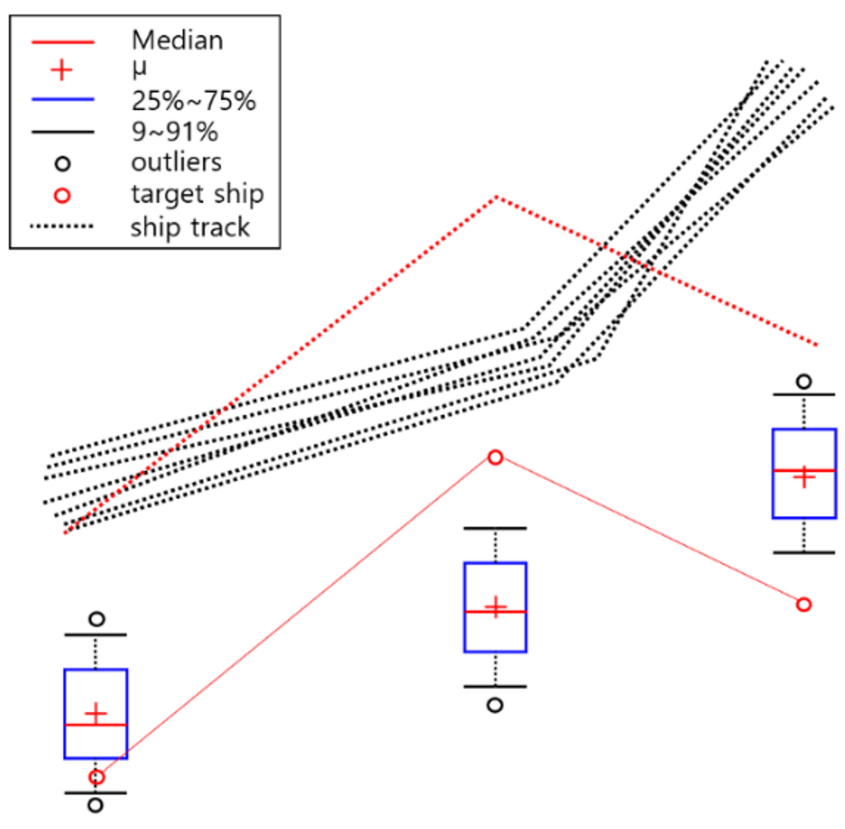

Figure 4. Anomalous behavior detection method.

91\%-100\% shall be the abnormal navigation level. Meanwhile, the values of the limitations can be adjusted according to the regional characteristics.

\section{Simulation}

In order to verify the proposed method, it was constructed for a virtual route and targets that are similar to the actual navigational environment. As shown in Figure 5, the virtual route was modeled after the eastern passage of Incheon harbor in Korea. The route has gently curved sections, and there are many obstacles in navigation such as shallow water zones, rocks and islands. A ship navigating in this route frequently changes its course and speed for running curves. The area has appropriate navigational environment to test the proposed method.

The result of extracting the traffic model according to the proposed method is shown in Figure 6(a). Figure 6(b) is the result of comparison with the extracted course model and the target ship. Figure 6(c) shows the result of comparison of the extracted speed model and the target ship's speed changes. Simulation results showed that the course or speed data were found abnormal before the ship's trajectory deviated from the reference route.

Figure 7 and Table 2 show the result of anomalous behavior detection. Figure 7(a) is the result of detection of position abnormalities, Figure 7(b) is course, and Figure 7(c) is result of 


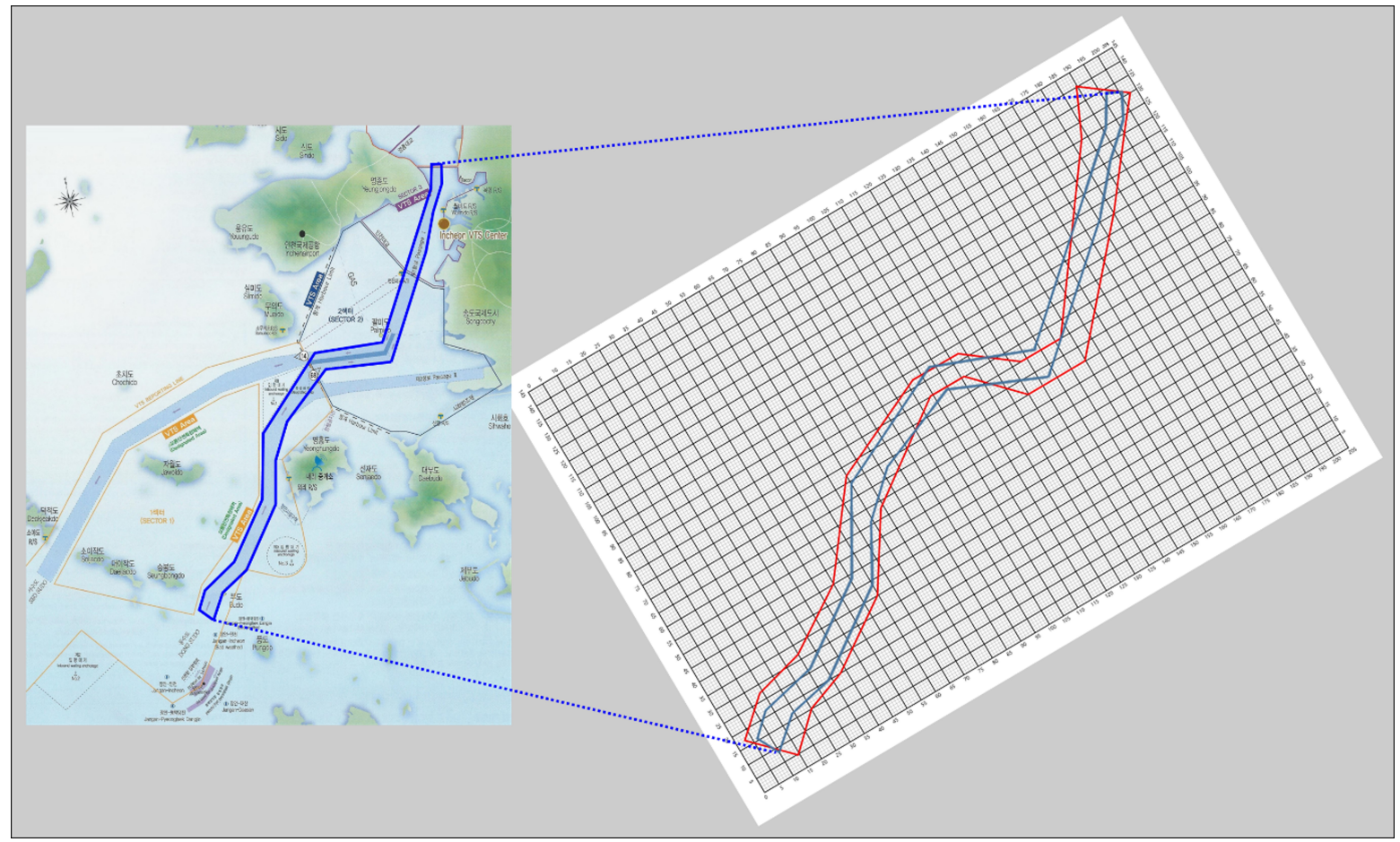

Figure 5. Simulation route configuration.

speed detection. Table 2 is the result of abnormal data detection. After $17^{\prime} 42^{\prime \prime}$ from the initiation of navigation, the course difference of the target was first exceed above the set value. After $58^{\prime \prime}$, target's position was started to show abnormalities. It means that it could be predicted and the target's anomalous behavior started $58^{\prime \prime}$ before breakaway. At $27^{\prime} 14^{\prime \prime}$, the maximum value of course difference was detected. After $61^{\prime \prime}$, the target's deviation was the highest level and the maximum value of speed difference was found at $36^{\prime} 43^{\prime \prime}$.

\section{Conclusion}

The anomalous behavior detection of a ship is an important reference data for deciding the action to be taken by the ship's operators and VTSOs. The conventional method of determining the anomalous behavior cannot guarantee the reliability because the user arbitrarily determines the criteria. Additionally, there is a limitation to the setting of criteria for application in various navigational environments. In this study, it was proposed for a method to determine the anomalous behavior based on the SVR seaway model. The navigational data such as the position, course and speed were learned and the reference data were extracted to determine the anomalous behavior. In order to verify the performance of the proposed method, it was constructed for a virtual route and ships which are similar to the actual navigational environment.

Since the proposed method is based on the data learning, it could be changed according to the collected and stored datasets. It means that the reference data are not fixed, and it can be changed appropriately according to the navigational environment and the periods. It is a decision making support tool that can judge the anomalous behavior based on the valid reference value to the user. However, if such navigational data for learning are not obtained in advance, it would be impossible to set the reference value. In addition, it is also impossible to distinguish the intended anomaly such as adjusting the deviation and avoiding the traffic situation. In the further research, it is necessary to develop an improved method for determining anomalous behavior that comprehensively reflects the navigational data to detect the intended abrupt action by crew.

\section{Acknowledgments}

This research was supported by the Next-Generation Information Computing Development Program through the National Research Foundation of Korea (No. NRF-2017M3C4A7069432) and by Basic Science Research Programs through the National Research Foundation of Korea (NRF) funded by the Ministry of Education (No. NRF-2016R1A6A3A11935806). 

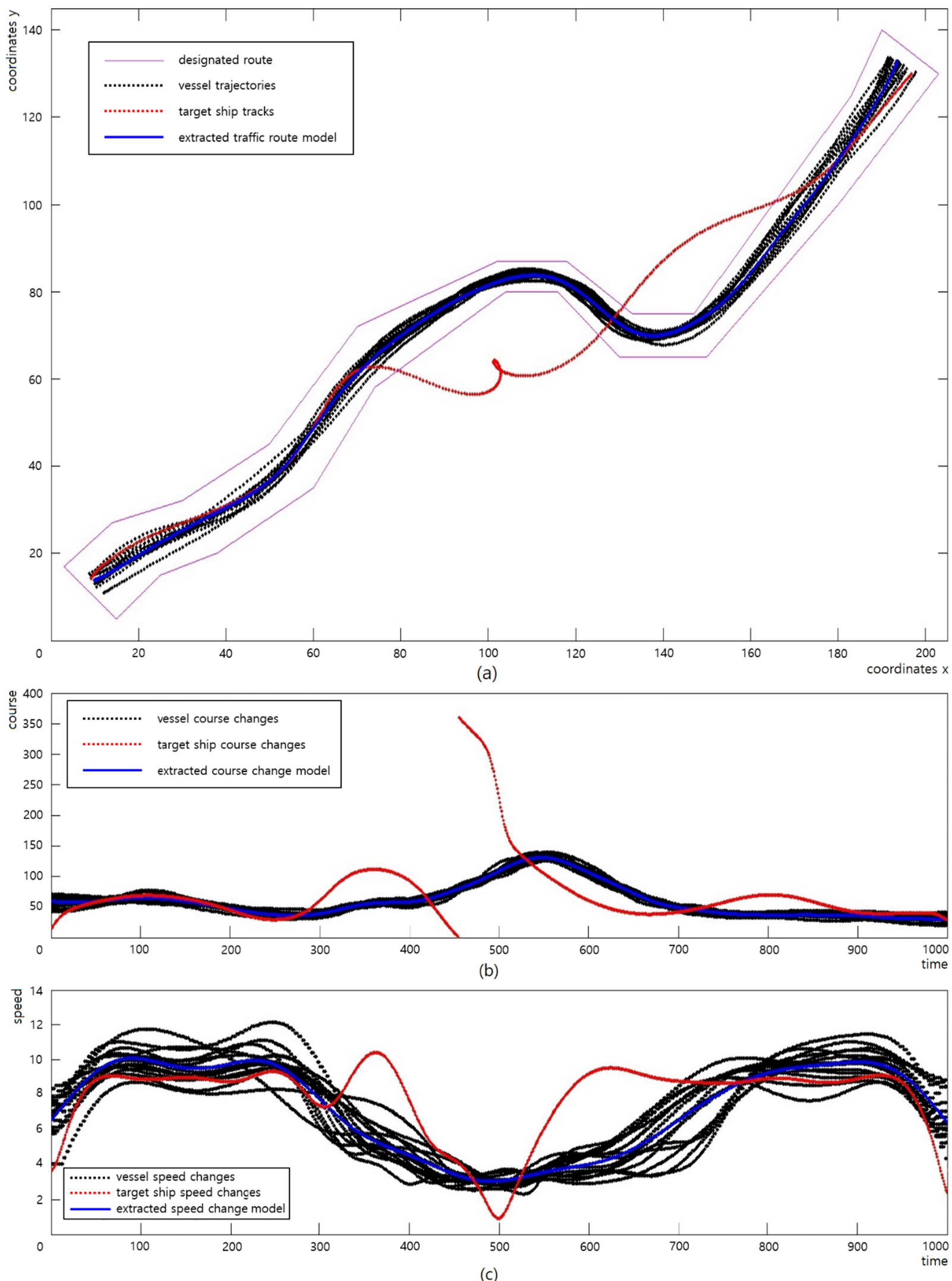

Figure 6. Simulation result of virtual route: (a) trajectory configuration and navigational data learning, (b) course data learning and result, and (c) speed data learning and result. 

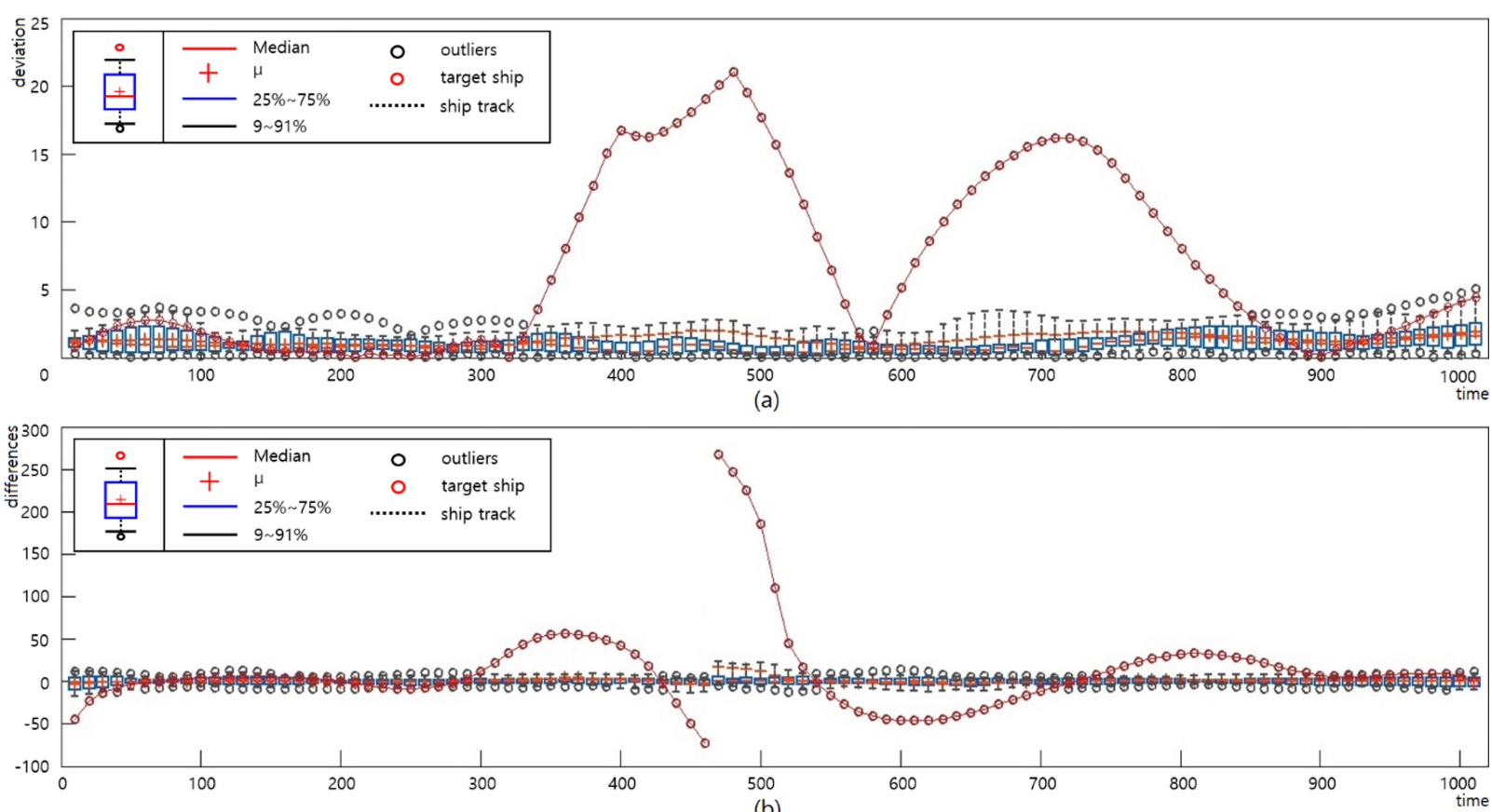

(b)

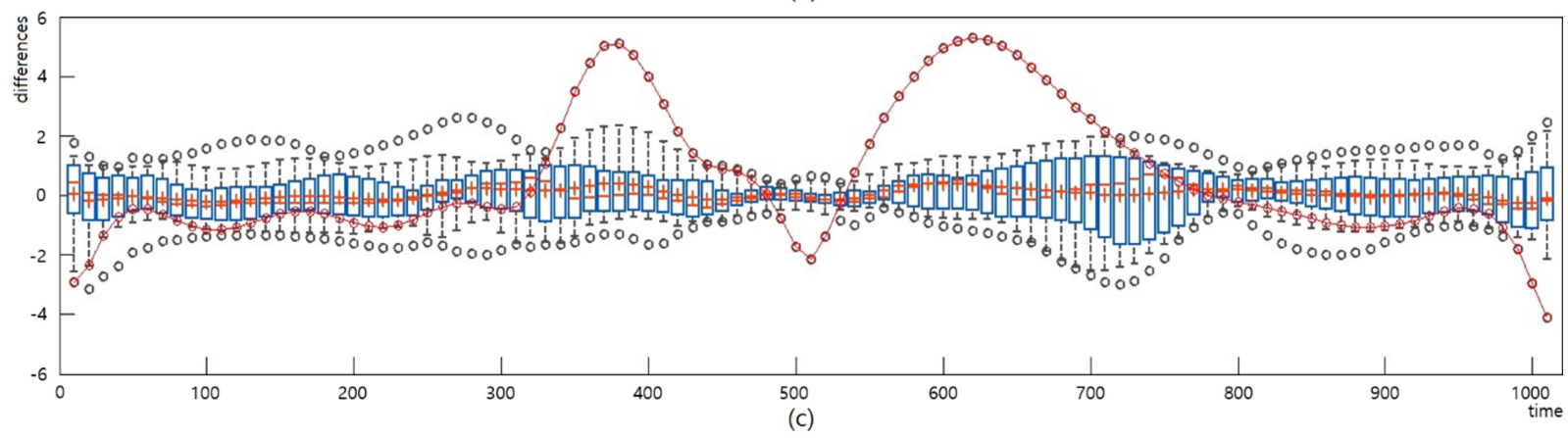

Figure 7. Result of anomalous behavior detection: (a) position deviation, (b) course differences, and (c) speed differences.

Table 2. Detected anomalous behavior

\begin{tabular}{ccccl}
\hline Time & $\begin{array}{c}\text { Deviation } \\
\text { (cables) }\end{array}$ & $\begin{array}{c}\text { Course difference } \\
\text { (cables) }\end{array}$ & $\begin{array}{c}\text { Speed difference } \\
\text { (knots) }\end{array}$ & \multicolumn{1}{c}{ Remarks } \\
\hline $17 \mathrm{~min} 42 \mathrm{sec}$ & 1.288325 & 15.57046 & -0.46404 & The first abnormal course data was detected. \\
$19 \mathrm{~min} 44 \mathrm{sec}$ & 3.166603 & 49.91429 & 2.023567 & The first abnormal position data was detected. \\
$27 \mathrm{~min} 14 \mathrm{sec}$ & 19.36078 & -78.4007 & 0.744299 & Maximum course difference was found. \\
$28 \mathrm{~min} 15 \mathrm{sec}$ & 21.03332 & 246.5291 & 0.029139 & Maximum deciation was found. \\
$36 \mathrm{~min} 43 \mathrm{sec}$ & 8.763354 & -45.1824 & 5.276219 & Maximum speed difference was found. \\
\hline
\end{tabular}

\section{References}

[1] Korean Maritime Safety Tribunal, "Annual Report of Marine Accident 2018," 2018; https://www.kmst.go.kr/kmst/ statistics/annualReport/selectAnnualReportList.do

[2] International Maritime Organization, Guidelines for Vessel Traffic Services, IMO Resolution A.857(20). London:
International Maritime Organization, 1997.

[3] Korea Ministry of Government Legislation, Act of Ship Arrival and Departure, 2015.

[4] Korea Ministry of Government Legislation, Maritime Safety Law, 2015. 
[5] Korea Coast Guard, Vessel Traffic Service Guidelines, 2017.

[6] N. Bowditch, The American Practical Navigator: Being an Epitome of Navigation and Nautical Astronomy. Charleston, SC: Nabu Press, 2013.

[7] M. Smith, "Anomaly detection in vessel track data," Master's thesis, University of Oxford Press, Oxford, UK, 2013.

[8] R. Laxhammar, "Anomaly detection in trajectory data for surveillance applications," PhD dissertation, Orebro University, Orebro, Sweden, 2011.

[9] V. S. Nguyen, V. C. Do, and N. K. Im, "Development of automatic ship berthing system using artificial neural network and distance measurement system," International Journal of Fuzzy Logic and Intelligent Systems, vol. 18, no. 1, pp. 41-49, 2018. https://doi.org/10.5391/IJFIS.2018. 18.1 .41

[10] K. I. Kim and K. M. Lee, "Context-aware information provisioning for vessel traffic service using rule-based and deep learning techniques," International Journal of Fuzzy Logic and Intelligent Systems, vol. 18, no. 1, pp. 13-19, 2018. https://doi.org/10.5391/IJFIS.2018.18.1.13

[11] D. Y. Kim, G. K. Park, J. S. Jeong, and G. U. Kim, "Implementation of an intelligent system for identifying abnormal navigating ships," Journal of Korean Institute of Intelligent Systems, vol. 22, no. 1, pp. 75-80, 2012. https://doi.org/10.5391/JKIIS.2012.22.1.75

[12] D. Y. Kim, K. Y. Kim, G. K. Park, and J. S. Jeong, "A study on the implementation of intelligent navigational risk assessment system for high-risk vessel using IoT sensor gateway," Journal of Korean Institute of Intelligent Systems, vol. 26, no. 3, pp. 239-245, 2016. https://doi.org/10.5391/JKIIS.2016.26.3.239

[13] J. Y. Oh, H. J. Kim, and S. K. Park, "Detection of ship movement anomaly using AIS data: a study," Journal of Korean Navigation and Port Research, vol. 42, no. 4, pp. 277-282, 2018.

[14] J. S. Kim, J. S. Jeong, and G. K. Park, "Utilization of planned routes and dead reckoning positions to improve situation awareness at sea," International Journal of Fuzzy Logic and Intelligent Systems, vol. 14, no. 4, pp. 288-294, 2014. https://doi.org/10.5391/IJFIS.2014.14.4.288
[15] J. S. Kim and J. S. Jeong, "Pattern recognition of ship navigational data using support vector machine," International Journal of Fuzzy Logic and Intelligent Systems, vol. 15, no. 4, pp. 268-276, 2015. https://doi.org/10.5391/ IJFIS.2015.15.4.268

[16] J. S. Kim and J. S. Jeong, "Extraction of reference seaway through machine learning of ship navigational data and trajectory," International Journal of Fuzzy Logic and Intelligent Systems, vol. 17, no. 2, pp. 82-90, 2017. https://doi.org/10.5391/IJFIS.2017.17.2.82

[17] J. S. Kim, "vessel target prediction method and dead reckoning position based on SVR seaway model," International Journal of Fuzzy Logic and Intelligent Systems, vol. 17, no. 4, pp. 279-288, 2017. https://doi.org/10.5391/IJFIS. 2017.17.4.279

[18] V. N. Vapnik, The Nature of Statistical Learning Theory. New York, NY: Springer, 1995.

[19] V. N. Vapnik, Statistical Learning Theory. New York, NY: John Wiley \& Sons, 1998.

[20] J. S. Kim, "A design of reference route model based on SVR through reconstruction of ship trajectories in VTS area," $\mathrm{PhD}$ dissertation, Mokpo National Maritime University, Mokpo, Korea, 2016.

[21] S. R. Gunn, "Support vector machines for classification and regression," University of Southampton, UK, 1998.

[22] H. Y. Han, Introduction to Pattern Recognition. Seoul, Korea: HANBIT Academy Inc., 2014.

[23] C. W. Hsu, C. C. Chang, and C. J. Lin, "A practical guide to support vector classification," Department of Computer Science, National Taiwan University, Taipei, Taiwan, 2003.

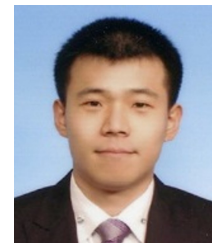

Joo-Sung Kim is a professor in the Division of Navigation Science at Mokpo National Maritime University in Korea. He received his B.S. degree in Nautical Science from Mokpo National Maritime University in Korea in 2004, his M.S. degree in International Maritime Transportation Sciences from Mokpo National Maritime University in Korea in 2014, and his Ph.D. degree in International Maritime Transportation Sciences from Mokpo National Maritime University in Korea in 2016. His research areas include 
intelligent system, fuzzy system, human factors engineering, work analysis, vessel traffic services, maritime transportation system, machine learning, pattern recognition, etc.

E-mail: jskim@mmu.ac.kr, jskim81@korea.kr

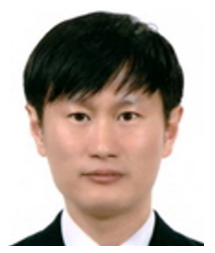

Jin-Suk Lee is a professor in the Division of Navigation Science at Mokpo National Maritime University in Korea. He received his B.S. degree in Division of Maritime Transportation Science from Korea Maritime University in Korea in 2003, his M.S. degree in Department of Maritime Traffic Information from Korea Maritime University in Korea in 2010, and his Ph.D. degree in Department of Navigation Science from Korea Maritime and Ocean University in Korea in 2017. His research areas include vessel traffic services, maritime transportation system, intelligent system, human fac- tors engineering, etc.

E-mail: jslee@mmu.ac.kr

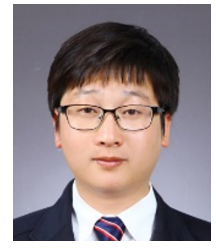

Kwang-Il Kim is a professor in the Division of Marine Industry and Maritime Police at Jeju National University in Korea. He received his B.S. degree in Nautical Science from Mokpo National Maritime University in Korea in 2005, his M.S. degree in International Maritime Transportation Sciences from Mokpo National Maritime University in Korea in 2012, and his Ph.D. degree in International Maritime Transportation Sciences from Mokpo National Maritime University in Korea in 2015. His research areas include intelligent system, vessel traffic services, maritime transportation system, maritime artificial intelligence, etc.

E-mail:kki@jejunu.ac.kr, setis0420@naver.com 